\title{
Encouraging Exploration, Creativity, and Joy through Compressed Engi- neering Immersion (Evaluation)
}

\section{Jenna Laleman, University of St. Thomas}

Jenna is a senior at the University of St. Thomas, finishing up her Bachelor's Degree in Elementary Education and STEM Education with a minor in Psychology. Jenna collaborates with the Center for Engineering Education to create outreach curriculum. She works in her university's Playful Learning Lab which focuses on engaging students of all ages in hands-on, innovative engineering education, especially focusing on reaching the underrepresented within the STEM fields. Jenna also leads the University's STEPS (Science, Technology, and Engineering Preview Summer) Program, developing the curriculum, leading the staff, and working as the primary researcher.

\section{Dr. AnnMarie Thomas, University of St. Thomas}

AnnMarie Thomas is a professor in the School of Engineering at the University of St. Thomas where she is the director of the UST Center for Engineering Education. Her research group, the Playful Learning Lab, focuses on engineering and design education for learners of all ages.

\section{Dr. Deborah Besser P.E., University of St. Thomas}

Dr. Besser, PE, ENV SP, holds a PhD in education and MS and BS in civil engineering. Currently, she is chair of civil engineering and the director of the Center for Engineering Education. Previous experience includes faculty positions in diverse universities where she has taught a variety of coursework including steel, timber, concrete and masonry design, construction, engineering economy, engineering graphics and engineering education. Prior to teaching, Dr. Besser, a licensed engineer, was a design engineer with HNTB-CA, where she worked on seismic retrofits and new design of high profile transportation structures. 


\title{
Encouraging Exploration, Creativity and Joy through Compressed Engineering Immersion (Evaluation)
}

\begin{abstract}
The University of St. Thomas has a mission of reaching underrepresented individuals in STEM fields and one mechanism is a free program for middle school girls. In June of 2017, 92 sixthgrade and eighth-grade girls attended the program, called STEPs which stands for Science Technology \& Engineering Preview Summer program. The program takes place in the university engineering labs and MakerSpace, and consists of engineering design challenges, social activities and student-centered inquiry lessons. Lessons are crafted to appeal to female students based on lessons detailed in existing literature of what draws women into underrepresented STEM fields. The program focuses on fostering opportunities for hands-on learning, a component that may be less accessible to female students, as well as peer communication and collaboration, which has been identified as often matching the preferred learning styles for many female students (Gollnick \& Chinn, 2013). Another key program component is experiences of how engineering is a field in which people can help others, a factor which has been identified as aligning with female interests and career aspirations (USDOC, 2011; Hubelbank 2007).
\end{abstract}

The program research focuses on three areas: 1 . The program's impact on short-term interest and knowledge in engineering/STEM; 2. The effectiveness of matching lessons to learning goals; and 3. Differences between sixth-grade students and eighth-grade students in success, interest in activities, and problem solving methods. Through pre-program and post-program surveys, students answered Likert-scale based questions and short answer questions about their attitudes, interests, and knowledge in STEM. An analysis of qualitative short-answer questions allowed for an evaluation of students' interests and aspirations and an understanding of how the program influenced participants' future aspirations. Short, semi-structured interviews added another dimension of program evaluation. Researchers found that students met learning objectives as they gained new content knowledge and skills in engineering. They also discovered that the program broadened students' perceptions and definition of engineering. This paper discusses the program's activities and looks at an in-depth evaluation of student data in order to understand the program's impact and its indication on how age may play a role in student learning and attitudes around STEM.

\section{Literature Alignment}

The goal of the STEPs program, which has been offered in different formats since 2000, has consistently been to reach students who are otherwise underrepresented in STEM (science, technology, engineering, math) fields, particularly females. The program focuses on young women because of the continuing challenge of attracting and retaining women in engineering. For example, mechanical engineering, the most popular engineering degree, graduates $8.8 \%$ females. (USDOL, 2014). During the 2014-2015 academic year, 78,300 men received bachelor's degrees in engineering while only 19,600 women did (NCES, 2017).

The program focuses on young women exclusively as a means of increasing female participation in STEM. In mixed-gendered groups, males tend to take a more dominant role, which does not 